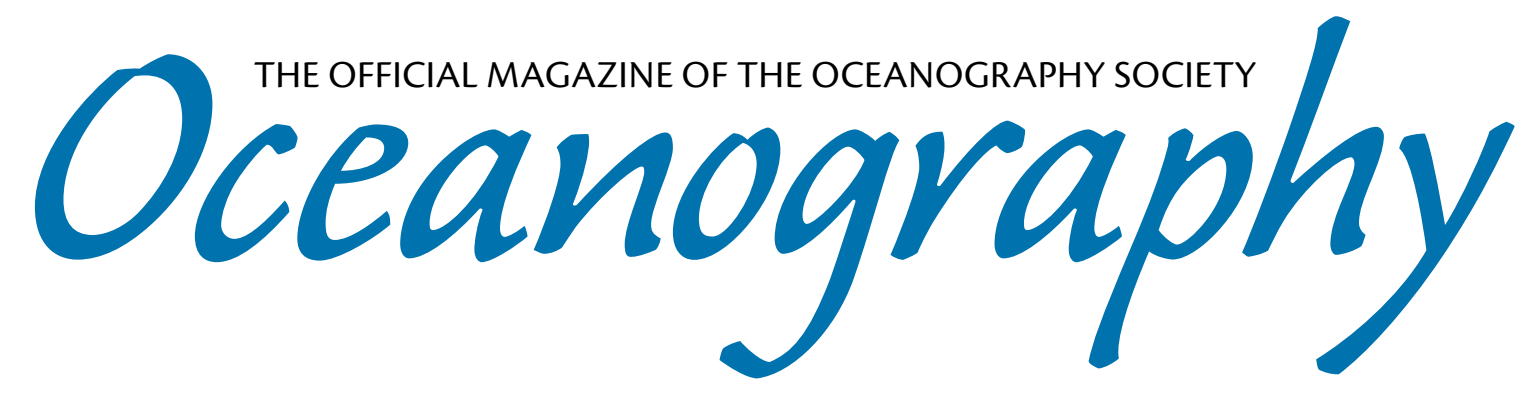

CITATION

Garrett, C. 2011. Review of The Power of the Sea: Tsunamis, Storm Surges, Rogue Waves,

and Our Quest to Predict Disasters, by B. Parker. Oceanography 24(1):180-182, doi:10.5670/

oceanog.2011.18.

\title{
COPYRIGHT
}

This article has been published in Oceanography, Volume 24, Number 1, a quarterly journal of The Oceanography Society. Copyright 2011 by The Oceanography Society. All rights reserved.

USAGE

Permission is granted to copy this article for use in teaching and research. Republication, systematic reproduction, or collective redistribution of any portion of this article by photocopy machine, reposting, or other means is permitted only with the approval of The Oceanography Society. Send all correspondence to: info@tos.org or The Oceanography Society, PO Box 1931, Rockville, MD 20849-1931, USA. 


\section{The Power of the Sea: Tsunamis, Storm Surges, Rogue Waves, and Our Quest to Predict Disasters}

By Bruce Parker, Palgrave Macmillan, 2010, 304 pages, ISBN 978-0-230-61637-0, Hardcover \$28, Kindle \$14.99 US.

\section{REVIEWED BY CHRIS GARRETT}

Bruce Parker is the former chief scientist of NOAA's National Ocean Service and is now a visiting professor at the Stevens Institute of Technology. As well as his personal contributions to topics such as tide prediction, in 1990 he organized a fine symposium on tidal hydrodynamics, with the proceedings published as a very useful volume with that title.

The present book, aimed at a general audience, is clearly a labor of love based on the author's passionate interest in the sea and his conviction of the value of prediction. This enthusiasm for the subject is conveyed in the book's subtitle and in a short introductory chapter entitled "When the sea turns against usescaping the sea's fury through prediction." In this chapter, he foreshadows topics such as the 2004 tsunami in the Indian Ocean and the 1970 storm surge in the Bay of Bengal, to be discussed in more detail later in the book.

The book's general approach, and one that will surely appeal to readers, is to introduce topics with historical accounts, blending in some science later. The first two chapters discuss ocean tides, now the most predictable contributors to sea level variations, though their rise and fall was not always anticipated. Parker's first anecdote concerns Napoleon's near loss of a group of soldiers to the rising tide on a crossing of the northern end of the Gulf of Suez. He then argues that Moses was a wily tidal expert who knew that he could lead his followers to safety at a low spring tide and count on the rising tide to deal with the less-expert pursuing Pharaoh. The "east wind that blew all night" was perhaps a minor part of the story. Parker's extensive scholarship is apparent; it's fun to find a reference to a paper entitled "William the Bastard at war," referring here to the use of a rising tide to split enemy forces by the gentleman whose later invasion of England in 1066 led to a change in his sobriquet to William the Conqueror.

The discussion of the historical development of tidal theory and prediction is nicely done, though less comprehensive than that in David Cartwright's Tides: A Scientific History (Cambridge University Press, 2001). The physics is sometimes a little weak; the claim that the resonant period of the Atlantic Ocean is 19 hours seems dubious, as there are many modes, with those near the tidal forcing frequencies dominating the response. The development of tidal bores is ascribed to the faster shallowwater propagation of wave crests rather than wave troughs, leading to a steepening of the front of an advancing tidal wave. This is actually only a third of the correct explanation, with the other twothirds due to faster currents at the crest; the steepening is one-third propagation and two-thirds advection.

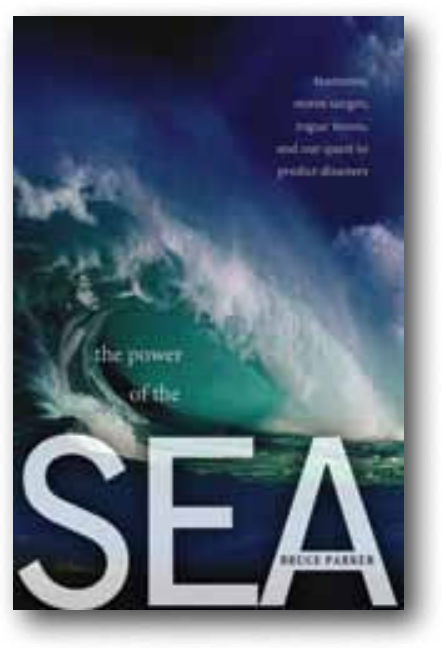

As in the first chapter, the historical accounts in the second chapter on tides will be new to many readers. The extremely low tide during the evening of the Boston Tea Party meant that the tea dumped overboard piled up on the seafloor next to ships that were grounded, though on later occasions the rebels were much smarter than the British in exploiting changing water levels and currents. Parker also analyzes the small apogean neap tides that led to the grounding of landing craft on a reef during the costly 1943 recapture by the US Marines of the island of Tarawa, and he writes about the role of tidal prediction in the date chosen for the D-Day Normandy landings. The Allied commanders wanted to land at first light, but also at low tide to allow for the clearing of underwater obstacles placed by Rommel, who was sure that the landings would occur at high tide to minimize the width of beach that needed to be crossed.

Chapters 3 and 4 move on to storm surges, "the sea's greatest killer" according to the title of Chapter 3 , which opens with an account of the disastrous 1864 cyclone and storm surge in the Bay of Bengal. The meteorological 
conditions, including barometric pressure readings from ships at sea, were well documented, but only after the event. Parker nicely describes a gradual increase in scientific understanding and predictability of storm surges in various parts of the world. Apparently, Benjamin Franklin was the first person to realize, in 1743 , that a storm could move in a direction opposite to that of the local wind.

Even before Katrina, the shortcomings of political appointments were illustrated by the 1900 storm surge at Galveston, where more than 6,000 people died, partly because the prediction by a reliable source in Cuba of a Gulf Coast hurricane landfall was ignored. Parker describes the move toward first statistical and then dynamical prediction schemes, motivated in northern Europe by the North Sea floods of 1953 and by similar events at many other locations around the world. He concludes that predictions have now reached a high level of accuracy, with the loss of human life more a function of the response of various levels of government to the predictions.

The next topic is surface waves, "Stormy seas-predicting sea, swell and surf" in Chapter 5 and "Holes in the surface of the sea-rogue waves" in Chapter 6. Parker's account opens with the 1942 story of the near capsize in a giant wave of the liner Queen Mary, while the ship was top-heavy with all the extra military equipment being sent to Europe along with thousands of American troops. He then describes the slow evolution of our understanding of how wind generates waves, how waves propagate, the effect of opposing currents in steepening them, and how oil damps at least the short waves. This discussion all leads into an account of the development of the Sverdrup-Munk scheme for forecasting wave heights at beaches where amphibious landings were planned in World War II, first on the Atlantic coast of North Africa and later in Normandy. The story is well told, but may be familiar to readers of Oceanography (see Munk and Day, 2002).

Interesting historical examples of ships other than RMS Queen Mary being affected, even sunk, by extreme waves are similar to those in other books, such as Craig Smith's Extreme Waves (Joseph Henry Press, 2006), but the science seemed to me to be a little muddled. It is never quite clear from the text whether rogue waves are: (1) any large waves, (2) waves in the tail of the probability distribution for waves in a particular sea state, or (3) waves in the tail occurring more frequently than standard theories predict (or, equivalently, waves with a particular occurrence rate that is larger than predicted). A footnote states that rogue waves are defined as waves twice as high as the significant wave height, as in (2) above, and that wave models have been unable to account for them; however, even the simplest linear model predicts that such waves occur every 3,000 waves or so. More frequent occurrence, as in (3) above, is the interesting problem scientifically and is, in fact, claimed by the reference Parker cites, but both observational evidence and theoretical explanation are still incomplete. Maybe it is as proclaimed recently in Canada's Globe and Mail newspaper, that "rogue waves operate outside the laws of physics"!

Parker devotes three chapters to tsunamis, starting with an apt heading
“The sea's response to an unpredictable Earth." He gives a dramatic account of the earthquake and tsunami in Lisbon on All Saints' Day (November 1) 1755. Between 30,000 and 60,000 people died. The disaster led to a debate as to whether it was God's punishment for sinners or a natural catastrophe. The latter interpretation became more acceptable five years later when the Reverend John Mitchell in Cambridge used arrival times of the tsunami around the Atlantic to locate the earthquake epicenter some 30 to 45 miles (48 to $72 \mathrm{~km}$ ) off the Portuguese coast. Parker discusses the basic physics of tsunami generation, interspersed with reviews of other historical events such as the 1888 eruption of Krakatoa. This topic has been discussed at length in books such as Simon Winchester's Krakatoa: The Day the World Exploded (HarperCollins, 2003), but Parker provides a nice summary and describes how warning systems have evolved, particularly in the Pacific with the deployment of bottom pressure sensors communicating with surface buoys.

The lack of a warning system in the Indian Ocean contributed to the huge loss of life in the December 26, 2004, tsunami in the Indian Ocean. Parker devotes two chapters to this event, with detailed accounts of the human impact in affected countries. There is some discussion of the information provided by seismic waves, and mention is made of the role of refraction in affecting the amplitude of the tsunami, but other aspects are not included. Was the succession of waves completely a function of the source, or was it influenced by the weak dispersion of long waves? Did the tsunami come ashore as a breaking wave or a surge, and what determines which 
one? I would have welcomed more science in these chapters. There is one map of the arrival time of the first wave, but it occurs 30 pages after the start of the discussion, and the account lacks schematic diagrams that would aid the description of things like the relative motion of the two colliding tectonic plates during the event. Parker's discussion of the Indian Ocean tsunami ends with a discussion of prediction systems and a plea for more tsunami awareness in coastal communities at risk. He also suggests that a nearshore pressure sensor, sending a signal to a siren on shore when the bottom becomes dry or the water level quickly drops below that of the lowest tide, could provide a cheap and effective local warning system, at least in locations where the first arrival is a trough.

In the final chapter, "Predicting the future-and saving lives," Parker discusses the longer-period phenomena of El Niño and climate change, stressing the value of ocean observing systems, perhaps under the umbrella of the Global Ocean Observing System. He presents a sensible discussion at a popular level of the problems and perils of global warming and ocean acidification, stressing the need for action in spite of uncertainty. I found the discussion of sea level rise to be rather brief, especially as it is sea level that has really been the main topic of the book.

Parker suggests that renewable energy systems are the ultimate solution to many of our problems, and argues that their production would provide an economic stimulus similar to that of increased production of military equipment during World War II. He lists waves, tides, currents, and ocean thermal energy conversion (OTEC) among the possible sources of renewable energy, but without an oceanographic analysis that is likely to show that their potential is rather small compared with human needs or with other options such as solar and wind power. The public can easily be overoptimistic about things like this, so a quantitative evaluation in a popular book would be valuable.

Overall, I enjoyed this well-written book, particularly for the historical accounts. Parker has done a tremendous amount of background reading, as indicated by the 60 pages of references and notes at the end of the book. He pays tribute to the NOAA Federal Library in Silver Spring, Maryland, and graciously names and thanks individual librarians. He also thanks colleagues who read drafts, though a wider circle of readers might have helped correct the instances where the science is questionable. These corrections could all be dealt with in a second edition, of course.

If Parker contemplates a second edition, I would also urge the incorporation of the endnotes into the text, as many of them contain fascinating information. I don't need to see a reference, but I find it distracting to turn to an endnote or even a footnote while reading, or frustrating to wait until I've finished the chapter and then find that I've missed something interesting. Maybe if the material is considered secondary it could be printed in a different font so that a reader could quickly decide what to read and what to skip.

I think a revised edition would also benefit from more figures and diagrams. To be sure, the present edition does have some interesting illustrations, a few reproduced from rare publications, but the figures are limited in number (just 17), all black and white, and many a little fuzzy.

These issues are small for the Oceanography reader, who will almost surely enjoy the book, but its overall appearance might limit its appeal to many members of the public. Someone browsing in a bookstore and opening the book at random is also likely to find the text dense and unattractive. This is unfortunate; the book deserves the wider audience that I think could be achieved by repackaging. I hope that the author can convince his present publisher, or a different one, to consider this option.

Chris Garrett (cgarrett@uvic.ca) recently retired from the University of Victoria, Victoria, BC, Canada.

\section{REFERENCE}

Munk, W., and D. Day. 2002. Haruld U. Sverdrup and the war years. Oceanography 15(4):7-29. Available online at: http://www. tos.org/oceanography/issues/issue_archive/ issue_pdfs/15_4/15.4_munk_day.pdf (accessed January 12, 2011). 